\title{
Diagnostic electrocardiographic dyad criteria of emphysema in left ventricular hypertrophy
}

This article was published in the following Dove Press journal:

International Journal of Chronic Obstructive Pulmonary Disease

21 November 2013

Number of times this article has been viewed

\author{
Swapnil S Lanjewar' \\ Lovely Chhabra' \\ Vinod K Chaubey' \\ Saurabh Joshi' \\ Ganesh Kulkarni' \\ Chandrasekhar \\ Kothagundla' \\ Sudesh Kaul' \\ David H Spodick ${ }^{2}$ \\ 'Department of Internal Medicine, \\ ${ }^{2}$ Department of Cardiovascular \\ Medicine, Saint Vincent Hospital, \\ University of Massachusetts Medical \\ School, Worcester, MA, USA
}

Correspondence: Lovely Chhabra

Saint Vincent Hospital, University

of Massachusetts Medical School,

I23 Summer Street, Worcester,

MA 01608, USA

$\mathrm{Tel}+\mathrm{I} 5086675052$

Fax + I 8885986647

Email lovids@hotmail.com
Background: The electrocardiographic diagnostic dyad of emphysema, namely a combination of the frontal vertical P-vector and a narrow QRS duration, can serve as a quasidiagnostic marker for emphysema, with specificity close to $100 \%$. We postulated that the presence of left ventricular hypertrophy in emphysema may affect the sensitivity of this electrocardiographic criterion given that left ventricular hypertrophy generates prominent left ventricular forces and may increase the QRS duration.

Methods: We reviewed the electrocardiograms and echocardiograms for 73 patients with emphysema. The patients were divided into two groups based on the presence or absence of echocardiographic evidence of left ventricular hypertrophy. The P-vector, QRS duration, and forced expiratory volume in one second $\left(\mathrm{FEV}_{1}\right)$ were computed and compared between the two subgroups.

Results: There was no statistically significant difference in qualitative lung function $\left(\mathrm{FEV}_{1}\right)$ between the subgroups. There was no statistically significant difference in mean P-vector between the subgroups. The mean QRS duration was significantly longer in patients with left ventricular hypertrophy as compared with those without left ventricular hypertrophy.

Conclusion: The presence of left ventricular hypertrophy may not affect the sensitivity of the P-vector verticalization when used as a lone criterion for diagnosing emphysema. However, the presence of left ventricular hypertrophy may significantly reduce the sensitivity of the electrocardiographic diagnostic dyad in emphysema, as it causes a widening of the QRS duration.

Keywords: emphysema, electrocardiogram, left ventricular hypertrophy, chronic obstructive pulmonary disease, P-vector, QRS duration

\section{Introduction}

Chronic obstructive pulmonary disease is a syndrome in which chronic inflammatory changes of the lung airways and parenchyma cause progressive airflow limitation which is not fully reversible. ${ }^{1}$ To date, the association between various electrocardiographic abnormalities in emphysema has been well reported in prior studies, and a vertical P-vector $\left(>60^{\circ}\right)$ has been found to be the most sensitive lone electrocardiographic criterion for diagnosis of emphysema. ${ }^{2-8}$ Previous studies have shown that the vertical $\mathrm{P}$-vector is not only the most sensitive but also a highly specific criterion for rapid bedside screening for emphysema in the general hospitalized population. ${ }^{46}$ Moreover, a vertical P-vector also bears an inverse correlation with the severity of obstructive lung dysfunction (forced expiratory volume in one second, $\mathrm{FEV}_{1}$ ) and radiographic severity of emphysema. ${ }^{9,10}$ A vertical P-vector has a sensitivity and specificity ranging 
from $82.1 \%$ to $96 \%$ and from $86.4 \%$ to $96 \%$, respectively, for diagnosing emphysema. ${ }^{4,6,11-13}$

A narrow QRS is also a characteristic of emphysema. ${ }^{11}$ A QRS duration $<90$ msec has almost 100\% sensitivity and a QRS duration of $<70$ msec has almost $100 \%$ specificity in electrocardiographic screening for emphysema. ${ }^{11}$ The narrow QRS complex in patients with emphysema was first described in 1974. ${ }^{14}$ This observation was also correlated with computerized measurements of the QRS duration subsequently in $1999 .{ }^{6}$ In one of the recent investigations, a vertical P-vector and narrow QRS duration were utilized as an electrocardiographic diagnostic dyad for emphysema, and revealed a specificity close to $100 \%$ when the QRS duration was $<75 \mathrm{msec}$ in combination with a vertical P-vector. ${ }^{11} \mathrm{We}$ postulated that the presence of left ventricular hypertrophy (LVH) in emphysema may perturb the sensitivity of the diagnostic dyad criterion, given that LVH generates prominent left ventricular forces and may increase the QRS duration. Our current study aimed to investigate the same hypothesis in a clinical setting by testing the effects of LVH on the vertical $\mathrm{P}$-vector and QRS duration in patients with emphysema.

\section{Materials and methods}

We reviewed 12-lead electrocardiograms for 100 unselected, consecutive emphysema patients who received treatment for chronic obstructive pulmonary disease/emphysema at the pulmonary clinic, Saint Vincent Hospital, after application of initial selection criteria. Inclusion criteria were age $>45$ years and an established diagnosis of emphysema based on clinical history, pulmonary function tests, and radiologic investigations, including chest computed tomography or roentgenogram. Patients aged $<45$ years and those with poor quality electrocardiographic tracings, non-sinus rhythm, paced rhythms, or bundle branch blocks were excluded. Patients younger than 45 years were excluded because a vertical P-vector may be a normal physiologic finding in such patients. ${ }^{2,4}$ Of the 100 emphysema patients screened based on the initial selection criteria, 27 were excluded because they did not have an echocardiogram available in our database in the previous year. Thus, a total of 73 patients were finally enrolled in the study. Of these, 30 patients had LVH on echocardiography and 43 patients did not have LVH. A left ventricular posterior wall diameter and/or interventricular septal wall thickness $>11 \mathrm{~mm}$ was used as the echocardiographic criteria for diagnosis of LVH. ${ }^{15}$ Computer-generated $\mathrm{P}$ wave axes and QRS durations were noted and inspected manually by the authors independently using a handheld $10 \times$ loop magnifier. In the event of any discrepancy or suspected error in automated reading, manual readings were used. Manual calculation of frontal P-vectors was performed using the vector method, based on the amplitude of the P waves in leads I and III. 2,4,16

The duration of the QRS complex generated via computer was noted and corroborated manually by measuring the QRS duration from the beginning of the $\mathrm{Q}$ wave to the $\mathrm{J}$ point. Any differences in manual computations were subsequently resolved in a conference consensus.

Demographic variables including age, sex, and smoking history (pack-years) were reviewed from the medical charts of all patients and were then compared for any statistically significant difference between the subgroups, ie, emphysema patients without and with LVH. Mean P-vector, QRS duration, and $\mathrm{FEV}_{1}$ were also computed in all patients and then compared between the subgroups. The data were checked for skewness using the Mann-Whitney $U$ test. The P-vector, QRS duration, and $\mathrm{FEV}_{1}$ were compared in the subgroups using the unpaired Student's $t$-test for any statistically significant difference. Correlation between the P-vector and $\mathrm{FEV}_{1}$ was determined using the Pearson's correlation test. All calculations were done using GraphPad Prism 6 statistical software (GraphPad Software, San Diego, CA, USA). P-values (twosided $<0.05$ were considered to be statistically significant.

\section{Results}

The baseline demographics of the study population are shown in Table 1. The total number of patients in the study was 73 . The mean age ( \pm standard deviation) of the patients was $69.21 \pm 9.37$ years and their average smoking history was $60.81 \pm 29.98$ pack-years. The mean frontal P-vector for all patients was $67.71^{\circ} \pm 11.36^{\circ}$ and their average QRS duration was $83.88 \pm 10.68 \mathrm{msec}$. The mean $\mathrm{FEV}_{1}$ for all patients in the study was $48.55 \% \pm 17.85 \%$. The 73 patients were then subdivided into two groups, ie, emphysema without LVH and with LVH, as shown in Table 2. There was no statistically significant difference in mean frontal P-vector between the

Table I Patient demographic characteristics

\begin{tabular}{lll}
\hline $\begin{array}{l}\text { Variable } \\
\text { (for all patients) }\end{array}$ & $\begin{array}{l}\text { Emphysema } \\
\text { patients }(\mathrm{n}=73)\end{array}$ & $\begin{array}{l}\text { P-value } \\
\text { (two-sided) }\end{array}$ \\
\hline Age (years) & $69.21 \pm 9.37$ & \\
Smoking history (pack-years) & $60.81 \pm 29.98$ & \\
Frontal P-vector & $67.7 I^{\circ} \pm 11.36^{\circ}$ & \\
QRS duration (msec) & $83.88 \pm 10.68$ & \\
FEV $(\%)$ & $48.55 \pm 17.85$ & \\
$r\left(P\right.$-vector and $\left.F E V_{1}\right)$ & -0.56 & $P<0.00 I^{*}$ \\
\hline
\end{tabular}

Notes: Data are presented as the mean \pm standard deviation; $r$ indicates Pearson's correlation coefficient; *statistically significant $P$-value.

Abbreviation: $\mathrm{FEV}_{1}$, forced expiratory volume in one second. 
Table 2 Comparison of electrocardiographic diagnostic criteria and lung function variables in patients with and without LVH

\begin{tabular}{lllll}
\hline Variable & No LVH & LVH & P-value & Description \\
\hline $\begin{array}{l}\text { Frontal } \\
\text { P-vector }\end{array}$ & $68.42^{\circ} \pm 11.24^{\circ}$ & $66.7^{\circ} \pm 11.65^{\circ}$ & 0.53 & Two-tailed \\
$\begin{array}{l}\text { QRS duration } \\
\text { (msec) }\end{array}$ & $81.56 \pm 10.87$ & $87.67 \pm 10.97$ & $0.02^{*}$ & Two-tailed \\
$\begin{array}{l}\text { FEV }(\%) \\
r(P-v e c t o r\end{array}$ & $49.14 \pm 19.11$ & $47.7 \pm 16.16$ & 0.74 & Two-tailed \\
and FEV $)$ & -0.546 & -0.599 & & \\
\hline
\end{tabular}

Notes: Data are presented as the mean \pm standard deviation; $r$ indicates Pearson's correlation coefficient; *statistically significant $P$-value.

Abbreviations: $\mathrm{FEV}$, forced expiratory volume in one second; $\mathrm{LVH}$, left ventricular hypertrophy.

subgroups, ie, $68.42^{\circ} \pm 11.24^{\circ}$ in the group without LVH versus $66.7^{\circ} \pm 11.65^{\circ}$ in the group with $\mathrm{LVH}(P=0.53)$. The mean QRS duration was significantly wider in the emphysema patients with LVH as compared with those without $\mathrm{LVH}$, ie, $81.56 \pm 10.87 \mathrm{msec}$ versus $87.67 \pm 10.97 \mathrm{msec}(P=0.02)$. The severity of obstructive lung dysfunction (percent $\mathrm{FEV}_{1}$ ) was comparable between the subgroups $(49.14 \% \pm 19.11 \%$ in patients without LVH versus $47.7 \% \pm 16.16 \%$ in those with LVH, $P=0.74)$. FEV1 and P-vector verticalization showed an inverse correlation in the subgroups $(r=-0.546$ in patients without LVH and -0.599 in patients with $\mathrm{LVH}$ ).

\section{Discussion}

The electrocardiographic diagnostic dyad of emphysema, namely a combination of the frontal vertical P-vector and a narrow QRS duration, can serve as a ready diagnostic marker for emphysema, with a specificity close to $100 \%$, as demonstrated in previous studies. ${ }^{11}$ Although several theories have been postulated previously to explain these electrocardiographic changes, none have been proven conclusively so far. Among these, the most plausible explanation for narrowing of the QRS segment is "left ventricular disuse atrophy" ${ }^{17}$ Under normal physiologic circumstances, ie, in the absence of significant right ventricular hypertrophy, the left ventricle is the main generator of the electromotive forces of the heart. However, in emphysema, the equidominance or predominance of right ventricular forces may lead to a tendency toward "less of left ventricular forces", leading to more rapid completion of ventricular depolarization, resulting in a narrow QRS duration on the surface electrocardiogram. ${ }^{11}$

To the best of our knowledge, our study is the first thus far to investigate if the presence of LVH in patients with emphysema could affect these electrocardiographic diagnostic criteria in a practical clinical setting. One may conceptually project that the atrial vector may also shift relatively leftward as a result of left ventricular disuse atrophy in emphysema. However, this does not appear to be the case in actual practice, as evident from the results of this study. Thus, P-vector verticalization can still effectively serve as a lone diagnostic criterion even in the presence of left ventricular disease. However, should the diagnostic dyad be used, a prior history of left ventricular disease must be accounted. This may practically apply to many patients, including a major subset of those with pre-existing hypertensive heart disease.

Although verticalization of the P-vector can be independently affected by the severity of obstructive lung disease, this did not appear to be a limiting/confounding factor in our study because patients in both subgroups had comparable pulmonary function test results when compared using $\mathrm{FEV}_{1}$.

We acknowledge some limitations to this study. Many patients did not have a high resolution computed tomography (CT) scan of the chest, which is currently the gold standard for diagnosis of emphysema. Further, our investigation lacked a control group, in that all patients had a diagnosis of emphysema.

\section{Conclusion}

The electrocardiographic diagnostic dyad (P-vector verticalization with an axis $>60^{\circ}$ and a narrow QRS duration $<80 \mathrm{msec}$ ) can be effectively used to diagnose emphysema. However, one must take into consideration the presence or absence of left ventricular disease, mainly LVH. The presence of LVH may not affect the sensitivity of P-vector verticalization when used as a lone criterion for diagnosing emphysema. However, when used in combination with a narrow QRS duration (diagnostic dyad), it may significantly reduce the sensitivity as $\mathrm{LVH}$ causes widening of the QRS duration even in the setting of pre-existing emphysema.

\section{Disclosure}

The authors report no conflicts of interest in this work.

\section{References}

1. Barnes PJ. Chronic obstructive pulmonary disease. $N$ Engl J Med. 2000;343:269-280.

2. Spodick DH. Electrocardiographic studies in pulmonary disease. I. Electrocardiographic abnormalities in diffuse lung disease. Circulation. 1959;20:1067-1072.

3. Zuckerman R, Cabrera CE, Fishleder BL, Sodi-Pallares D. The electrocardiogram in chronic cor pulmonale. Am Heart J. 1948;35: 421-425.

4. Chhabra L, Sareen P, Perli D, Srinivasan I, Spodick DH. Vertical P-wave axis: the electrocardiographic synonym for pulmonary emphysema and its severity. Indian Heart J. 2012;64:40-42.

5. Spodick DH. Vectorcardiogram in pulmonary emphysema: its relation to scalar electrocardiographic findings. Am Rev Respir Dis. 1968;98: 634-639. 
6. Baljepally R, Spodick DH. Electrocardiographic screening for emphysema: the frontal plane P axis. Clin Cardiol. 1999;22:226-228.

7. Chhabra L, Chaubey VK, Kothagundla C, Bajaj R, Kaul S, Spodick DH. P-wave indices in patients with pulmonary emphysema: do P-terminal force and interatrial block have confounding effects? Int $J$ Chron Obstruct Pulmon Dis. 2013;8:245-250.

8. Chhabra L, Spodick DH. Transient super-Himalayan P-waves in severe pulmonary emphysema. J Electrocardiol. 2012;45:26-27.

9. Chhabra L, Sareen P, Gandagule A, Spodick D. Computerized tomographic quantification of chronic obstructive pulmonary disease as the principal determinant of frontal P vector. Am J Cardiol. 2012;109: 1046-1049.

10. Chhabra L, Sareen P, Gandagule A, Spodick DH. Visual computed tomographic scoring of emphysema and its correlation with its diagnostic electrocardiographic sign: the frontal $\mathrm{P}$ vector. $J$ Electrocardiol. 2012;45:136-140.

11. Thomas AJ, Apiyasawat S, Spodick DH. Electrocardiographic detection of emphysema. Am J Cardiol. 2011;107:1090-1092.
12. Lazovic B, Mazic S, Stajic Z, Djelic M, Zlatkovic-Svenda M, Putnikovic B. United in Prevention - electrocardiographic screening for chronic obstructive pulmonary disease. Acta Inform Med. 2013;21: $127-128$.

13. Chhabra L, Spodick DH. Electrocardiographic screening of emphysema: lead aVL or leads III and I? Acta Inform Med. 2013;21:223-223.

14. Zambrano SS, Moussavi MS, Spodick DH. QRS duration in chronic obstructive lung disease. J Electrocardiol. 1974;7:35-36.

15. Kumar D, Bajaj R, Chhabra L, Spodick DH. Refinement of total 12-lead QRS voltage criteria for diagnosing left ventricular hypertrophy. World J Cardiovasc Dis. 2013;3:210-214.

16. Chhabra L, Bajaj R, Chaubey VK, Kothagundla C, Spodick DH. Electrocardiographic impacts of lung resection. J Electrocardiol. July 3, 2013.

17. Spodick DH. Pericardial macro- and microanatomy. In: Spodick DH, editor. The Pericardium: A Comprehensive Textbook. New York, NY: Marcel Dekker; 1997.

\section{Publish your work in this journal}

The International Journal of COPD is an international, peer-reviewed journal of therapeutics and pharmacology focusing on concise rapid reporting of clinical studies and reviews in COPD. Special focus is given to the pathophysiological processes underlying the disease, intervention programs, patient focused education, and self management protocols.

\section{Dovepress}

This journal is indexed on PubMed Central, MedLine and CAS. The manuscript management system is completely online and includes a very quick and fair peer-review system, which is all easy to use. Visit http://www.dovepress.com/testimonials.php to read real quotes from published authors. 